\title{
Liquid-liquid Extraction and Recovery of Pd(II) from Nitric Acid Medium Using Green Diesel as Extractant
}

Botros Abdelnaser Masry, ${ }^{1}$ Mohammad Mohammad Zeid, ${ }^{1}$ Amany Taghian Kassem, ${ }^{1}$

Hala Gamal Noweir, ${ }^{1}$ Ebtissam Ahmad Saad ${ }^{2}$ and Jacqueline Abdel Messih Daoud ${ }^{1 *}$

${ }^{1}$ Hot Laboratories Centre, Atomic Energy Authority, 13759 Cairo, Egypt

${ }^{2}$ Department of Chemistry, Faculty of Science, Ain Shams University, 11566 Cairo, Egypt

*Corresponding author: jadaoud@yahoo.com

Published online: 25 August 2018

To cite this article: Masry, B. A. et al. (2018). Liquid-liquid extraction and recovery of Pd(II) from nitric acid medium using green diesel as extractant. J. Phys. Sci., 29(2), 25-48, https://doi.org/10.21315/jps2018.29.2.3

To link to this article: https://doi.org/10.21315/jps2018.29.2.3

\begin{abstract}
A cost-effective method for the extraction of palladium (Pd) from $\mathrm{HNO}_{3}$ solution by green diesel as extractant in kerosene was investigated. Several parameters such as extractant, nitrate, hydrogen ion, nitric acid and metal ion concentrations, phase ratio, and thermodynamic parameters were studied. The extracted species were deduced using slope analysis method and infrared (IR) measurements. The results showed that the extraction efficiency of Pd(II) is $95 \%$ with $10 \%(\mathrm{v} / \mathrm{v})$ diesel in kerosene, and $97 \%$ was recovered from the loaded organic solution using $0.05 \mathrm{M}$ thiourea or ammonium thiocyante solutions as stripping agents. The maximum loading capacity of diesel was found to be $2 \times 10^{-2}$ moles of Pd(II) per mole extractant. The effect of diluents on the extraction of Pd(II) from nitric acid solution by green diesel indicated that, under the used experimental conditions, kerosene gave the highest extraction percent compared to cyclohexane, benzene, toluene, chloroform and carbon tetrachloride. Extraction of Pd(II) from different acidic media was also carried out and the extraction percent was found to decrease in the order: $\mathrm{H}_{2} \mathrm{SO}_{4}>\mathrm{HNO}_{3}>\mathrm{HCl}$. The possibility of extraction and recovery of $\mathrm{Pd}$ from the sulphate leach solution of spent automotive catalyst was explored and a modified process is proposed and evaluated.
\end{abstract}

Keywords: Green diesel, palladium, nitric acid, extraction, automotive catalyst

\section{INTRODUCTION}

Nowadays, extraction and recovery of precious metals, especially palladium $(\mathrm{Pd})$, from wastes of industrial and nuclear applications are of major concern due to their scarcity and economic value. Pd has unique physical and chemical properties 
that are suitable for manufacturing industrial materials such as catalysts, electrical and corrosion-resistant alloys. ${ }^{1} \mathrm{Pd}$ is also very important in fuel cell industry. Therefore, it is important to develop an effective and cheap recovery process for Pd from nuclear and industrial applications. Among the most simple and efficient techniques which can be employed for the separation and recovery of Pd ions is solvent extraction process, which has already been industrially used for the recovery of precious metals in industrial scale. ${ }^{2}$ In this context, the extraction of $\mathrm{Pd}(\mathrm{II})$ from nitric acid medium with various ketones in nitrobenzene has been reported. ${ }^{3}$ The authors concluded that both methylalkylketones and ketones containing symmetrical alkyl configuration effectively extracted Pd(II) from nitric acid medium, especially 2-tridecanone and 2-nonanone which exhibited efficient extraction of $\mathrm{Pd}(\mathrm{II})$ and provided a feasible extraction system at $3.0 \mathrm{M}$ ligand concentration and $\mathrm{HNO}_{3}$ above $2.0 \mathrm{M}$.

Extraction of $\mathrm{Pd}$ from aqueous nitrate solution was studied with solvents containing 3,4-dithio toluene $\left(\mathrm{H}_{2} \mathrm{TDT}\right)$, bis(2,4,4-trimethylpentyl) monothiophosphinic acid (CYANEX 302) and its dithio analogue (CYANEX 301). ${ }^{4}$ The selectivity of Pd separation from nitric acid took the sequence $\mathrm{H}_{2}$ TDT $>$ CYANEX $301>$ CYANEX 302 in kerosene. ${ }^{4}$ CYANEX 302 provided good extraction performance as a carrier where almost $100 \%$ Pd was extracted and $90 \%$ was stripped with $2.0 \mathrm{M}$ thiourea in $1.0 \mathrm{M}$ sulfuric acid as stripping solution. ${ }^{1}$ The extraction of $\mathrm{Pd}(\mathrm{II})$ from $\mathrm{HNO}_{3}$ solution with 1-benzoyl-3- [6-(3-benzoyl-thioureido)-hexyl]-thiourea (Ia) and several monodentate thiourea derivatives in 1,2-dichloroethane has been studied; the increase in the number of thioamide groups in the molecule of Ia increased its extraction efficiency towards $\mathrm{Pd}(\mathrm{II}) .{ }^{5}$ Extraction and separation of $\mathrm{Pd}$, platinum (Pt) and rhodium (Rh) using CYANEX 923 and their recovery from real samples was carried out. ${ }^{6}$ The extraction behaviour of $\mathrm{Pd}(\mathrm{II})$ showed a positive dependence on the acidity of sulphuric acid indicating that the use of sulphuric acid favoured the formation of extractable species. ${ }^{6}$ The extraction studies of $\mathrm{Pd}$ from hydrochloric acid $(\mathrm{HCl})$ medium with triphenylphosphine $\left(\mathrm{Ph}_{3} \mathrm{P}\right)$, triphenylphosphine oxide $\left(\mathrm{Ph}_{3} \mathrm{PO}\right)$ or triphenylphosphine sulphide $\left(\mathrm{Ph}_{3} \mathrm{PS}\right)$ showed high extraction of $\mathrm{Pd}(\mathrm{II})$ with $\mathrm{Ph}_{3} \mathrm{P}^{7}$ The authors reported that the use of $1 \mathrm{M}$ stabilised thiosulfate solution was efficient for stripping Pd from its loaded $\mathrm{Ph}_{3} \mathrm{P}$-benzene solution. The selective extraction of Pd from nitric acid medium using CYANEX 471X in kerosene using n-octanol as modifier was carried out. ${ }^{8}$ The extraction from other acidic media indicated that the extraction decreased in the order sulphuric $>$ nitric $>$ hydrochloric acids. $^{8}$

The extraction performance and separation behaviour of $\mathrm{Pd}(\mathrm{II})$ and $\mathrm{Pt}(\mathrm{IV})$ were studied using a synthetic sulfoxide (MSO) as extractant from $\mathrm{HC} 1$ medium. The $\mathrm{Pd}(\mathrm{II})$ transfer depended strongly on the $\mathrm{MSO}$ and $\mathrm{HCl}$ concentration, phase 
ratio, contact time and $\mathrm{Pd}(\mathrm{II})$ concentration in stock solution. ${ }^{9}$ Phosphonium ionic liquids such as trihexyl (tetradecyl) phosphonium chloride and bromide (Cyphos IL 101 and 102) and bis-(2,4,4-trimethylpentyl) phosphinate (Cyphos IL 104) were used for the removal of $\mathrm{Pd}(\mathrm{II})$ ions from aqueous chloride solutions by liquidliquid extraction and transport across polymer inclusion membranes (PIM). ${ }^{10}$ The results showed that the addition of $\mathrm{NaCl}$ and the increase in $\mathrm{HCl}$ content in the feed aqueous phase slightly reduced the efficiency of $\mathrm{Pd}(\mathrm{II})$ extraction. In addition, CyphosIL 101 was used in the presence of toluene to extract Pd(II) from HC1 solutions of various concentrations. ${ }^{11}$ Successful stripping of $\mathrm{Pd}(\mathrm{II})$ from the loaded organic phase was achieved with $0.5 \mathrm{M}$ ammonia solution and CyphosIL 101 could be reused for at least 5 cycles of extraction-stripping processes. ${ }^{11}$

Green diesel is known to be a cheap source of sulphide extractants and has been used as extracting agent for liquid-liquid extraction of Pd from nitric acid mixtures. Such use has been proposed as a mean of separating the fission product Pd from PUREX raffinate which comes from spent nuclear fuel. ${ }^{12}$ Diesel oil in benzene and lacquer petroleum were used for an effective extraction of $\mathrm{Pd}(\mathrm{II})$ from nitrate medium and the authors reported that the distribution was almost independent of the acidity and nitrate concentration in the aqueous phase. ${ }^{13}$

In the present work, the solvent extraction of Pd ions from nitric acid medium using green diesel in kerosene has been studied. The effects of several parameters, such as the shaking time, acid concentration, diluent type, nitrate ion, hydrogen ion and extractant concentration, as well as temperature, were separately investigated. The stoichiometry of the extracted species was deduced using the slope analysis method and verified by Fourier transform infrared (FTIR) measurements. Stripping of Pd from loaded organic solutions was also carried out. Extraction of Pd(II) from sulphate and chloride media was investigated and the results were compared with those obtained in case of nitric acid medium. Based on the obtained results, the possible use of the studied system for the extraction and recovery of $\mathrm{Pd}(\mathrm{II})$ from spent automotive catalyst leached with sulfuric acid was explored and a developed recovery process is proposed and evaluated.

\section{EXPERIMENTAL}

\subsection{Chemicals}

Most of the chemicals and reagents used in this work are of analytical reagent (AR) grade and were used without further purification. $\mathrm{PdCl}_{2}$ was obtained from Fluka and nitric acid from BDH. Odourless non-aromatic kerosene was obtained from Misr Petroleum Company, Egypt. The commercial extractant (green diesel) 
was obtained from Total petroleum company, Egypt, and was used as received. Petroleum-derived diesel (green diesel) is composed of about $75 \%$ saturated hydrocarbons (primarily paraffins including $\mathrm{n}$, iso and cycloparaffins), and $25 \%$ aromatic hydrocarbons (including naphthalenes and alkylbenzenes). ${ }^{14}$ The average chemical formula for common diesel fuel is $\mathrm{C}_{12} \mathrm{H}_{23}$, ranging from $\mathrm{C}_{10} \mathrm{H}_{20}$ to $\mathrm{C}_{15} \mathrm{H}_{28}{ }^{15}$ Diesel oil is stable in nitric acid solution up to $5 \mathrm{M}$. At high acidity $(8 \mathrm{M})$, a possible oxidation of the extractant may take place leading to a slight decrease in its extraction properties. ${ }^{13}$

\subsection{General}

Pd concentration was measured with atomic absorption spectrometer (Thermo Scientific). Extraction experiments were carried out using a water-thermostated shaker of the type G.F.L 1083, Germany. The two phases were separated completely using a centrifuge of the type Z-230 obtained from Hermle, Germany.

\subsection{Liquid-liquid Extraction}

Extraction experiments were carried out by mixing equal volumes $(5 \mathrm{ml})$ of the aqueous phase $\left(9.40 \times 10^{-4} \mathrm{M} \mathrm{Pd}(\mathrm{II})\right.$ in $3 \mathrm{M}$ nitric acid) and organic phase $(0.25 \mathrm{M}(6 \%(\mathrm{v} / \mathrm{v})$ green diesel in kerosene as diluent and n-octanol as a modifier) using a water-thermostated shaker for $60 \mathrm{~min}$, which were found to be enough to reach equilibrium. After the disengagement of phases, the aqueous phase was analysed to determine the concentration of Pd using atomic absorption spectroscopy.

The general equation of extraction is the following:

$$
\mathrm{D}=\frac{[\mathrm{Pd}]_{\mathrm{i} \text { (aq.) }}-[\mathrm{Pd}]_{\mathrm{f}(\text { aq. })}}{[\mathrm{Pd}]_{\mathrm{i}(\text { aq. })}}
$$

where $\mathrm{D}$ is the distribution ratio of the Pd ions between the aqueous and organic phases, $[\mathrm{Pd}]_{\mathrm{i}(\mathrm{aq} .)}$ is the initial $\mathrm{Pd}$ concentration in the aqueous phase and $[\mathrm{Pd}]_{\mathrm{f}(\text { aq.) }}$ is the $\mathrm{Pd}$ concentration in the aqueous phase after extraction.

The percentage of extraction $(\% \mathrm{E})$ was determined from $\mathrm{D}$ values as:

$$
\% \mathrm{E}=\frac{100 \mathrm{D}}{D+\left(\mathrm{V} / \mathrm{V}^{\prime}\right)}
$$

where $\mathrm{V}$ and $\mathrm{V}^{\prime}$ denote the volume of the aqueous and organic phases, respectively. 
The stripping percent ( $\mathrm{S} \%$ ) was calculated as:

$$
\mathrm{S} \%=\frac{[\mathrm{Pd}]_{\mathrm{fs}(\mathrm{aq} .)}}{[\mathrm{Pd}]_{\mathrm{i}(\text { org. })}} \times 100
$$

where $[\mathrm{Pd}]_{\mathrm{fs}(\text { aq. })}$ is the $\mathrm{Pd}$ concentration in the aqueous phase after stripping and $[\mathrm{Pd}]_{\mathrm{i}(\text { org. }}$ is the $\mathrm{Pd}$ concentration in the organic phase after extraction.

\section{RESULTS AND DISCUSSION}

\section{1 $\quad$ Extraction of Pd(II)}

\subsubsection{Effect of shaking time}

The effect of shaking time on the extraction of $9.40 \times 10^{-4} \mathrm{M} \mathrm{Pd}(\mathrm{II})$ from $3 \mathrm{M} \mathrm{HNO}_{3}$ using $0.25 \mathrm{M}$ green diesel in kerosene was studied in the range of 5-160 min. The extraction percent was found to increase with the increase in time from $5 \mathrm{~min}$ to $60 \mathrm{~min}$. Further increase in the shaking time up to $160 \mathrm{~min}$ did not affect the extraction percent (Figure 1). Therefore, a shaking time of 60 min was maintained in all the extraction experiments of $\mathrm{Pd}(\mathrm{II})$ carried out in this work.

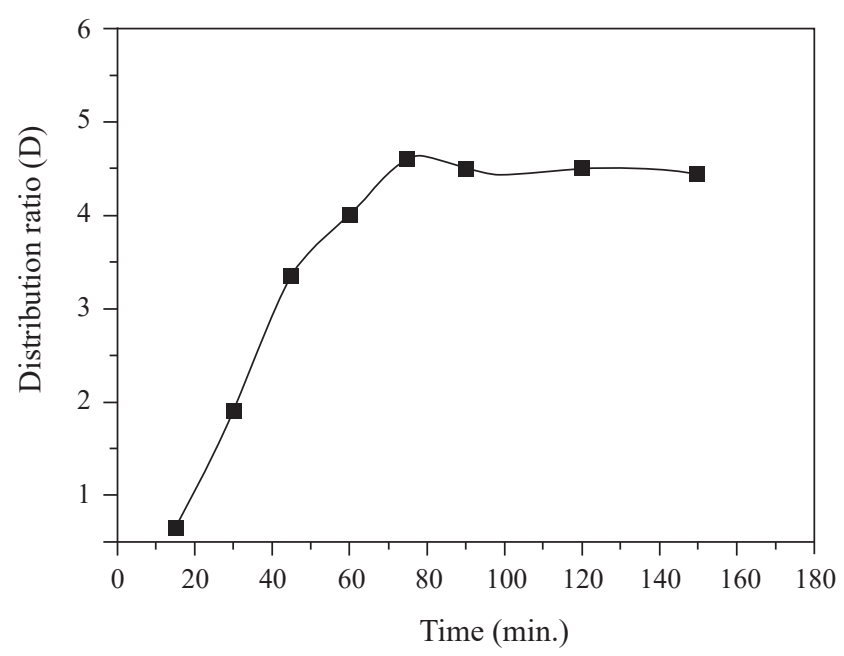

Figure 1: Effect of shaking time on the extraction of $\mathrm{Pd}(\mathrm{II})$ with green diesel in kerosene from $3 \mathrm{M}$ nitric acid solution; $\mathrm{O}: \mathrm{A}=1: 1, \mathrm{~T}=25^{\circ} \mathrm{C} \pm 1{ }^{\circ} \mathrm{C}$, [diesel $]=0.25 \mathrm{M}$, $[\mathrm{Pd}(\mathrm{II})]=9.4 \times 10^{-4} \mathrm{M}$. 


\subsubsection{Effect of green diesel concentration}

The effect of green diesel concentration on the extraction of $9.40 \times 10^{-4} \mathrm{M} \mathrm{Pd}(\mathrm{II})$ from $3 \mathrm{M} \mathrm{HNO}_{3}$ was studied in the range $0.085-0.42 \mathrm{M}(2 \%-10 \% \mathrm{v} / \mathrm{v})$. It was found that the extraction of Pd ions increased with the increase in the concentration of green diesel and reached a maximum of $95 \%$ when the concentration of extractant was $0.42 \mathrm{M}(10 \% \mathrm{v} / \mathrm{v})$. The plot of $\log \mathrm{D}$ vs. $\log$ [diesel] yielded a straight line of slope 1.99, which indicates that the extracted metal species contains two molecules of green diesel (Figure 2).

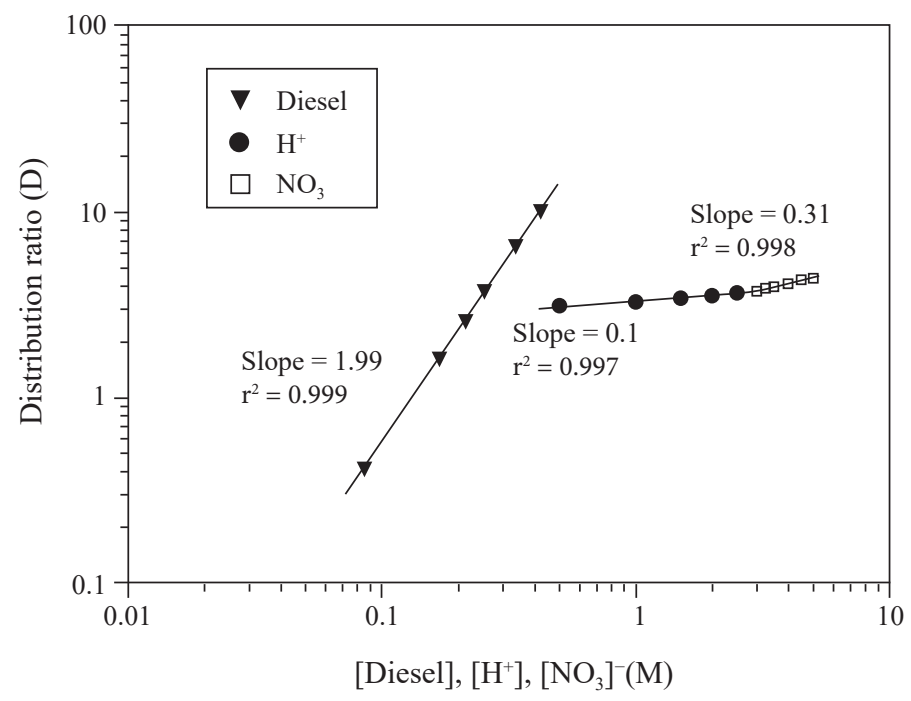

Figure 2: Effect of extractant, hydrogen ion and nitrate concentration on the extraction of $\mathrm{Pd}(\mathrm{II})$ from $3 \mathrm{M}$ nitric acid solution by green diesel in kerosene; $\mathrm{O}: \mathrm{A}=1: 1$, $\mathrm{T}=25^{\circ} \mathrm{C} \pm 1{ }^{\circ} \mathrm{C}$, shaking time $=60 \mathrm{~min},[\mathrm{Pd}(\mathrm{II})]=9.4 \times 10^{-4} \mathrm{M}$.

\subsubsection{Effect of nitric acid concentration}

The extraction behavior of $\mathrm{Pd}(\mathrm{II})$ by $0.25 \mathrm{M}$ green diesel from nitric acid solution of different concentrations ranging from $0.50 \mathrm{M}$ to $5.0 \mathrm{M}$ was carried out. The extraction percent of $\mathrm{Pd}(\mathrm{II})$ was found to increase from $53.50 \%$ to $80 \%$ at $3 \mathrm{M}$ nitric acid then remained nearly constant with further increase in the acid concentration, as shown in Figure 3. The increase in the extraction process in the low nitric acid concentrations may be due to the salting out effect of the nitrate ion which increases in the range $0.50-3.0 \mathrm{M}$ then becomes negligible at higher acidities leading to a constant extraction percentage. 


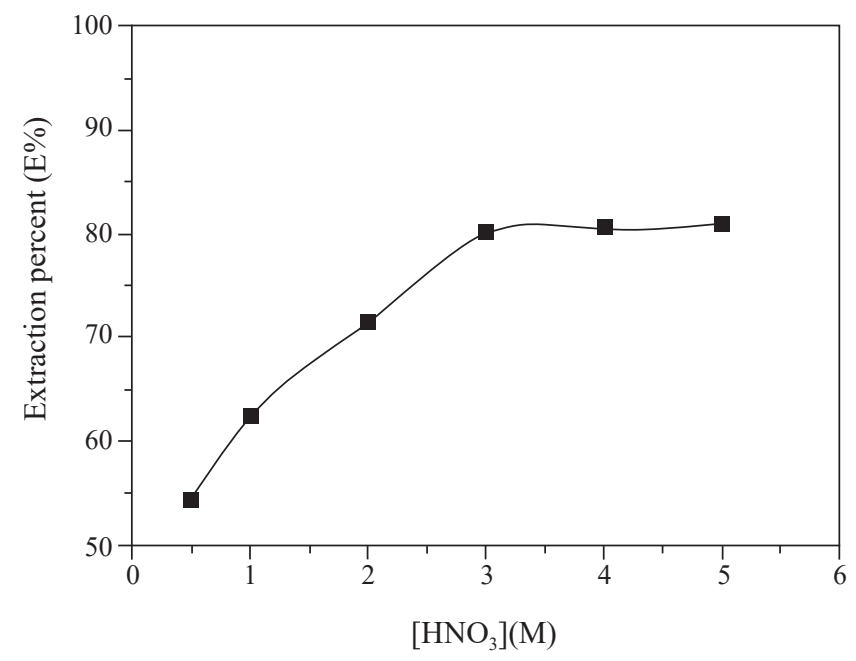

Figure 3: Effect of nitric acid concentration on extraction of $\mathrm{Pd}(\mathrm{II})$ by green diesel in kerosene; $\mathrm{O}: \mathrm{A}=1: 1, \mathrm{~T}=25^{\circ} \mathrm{C} \pm 1^{\circ} \mathrm{C}$, [diesel $]=0.25 \mathrm{M},[\mathrm{Pd}(\mathrm{II})]=9.4 \times 10^{-4} \mathrm{M}$, shaking time $=60 \mathrm{~min}$.

\subsubsection{Effect of hydrogen ion concentration}

The effect of hydrogen ion concentration on the extraction of $9.40 \times 10^{-4} \mathrm{M} \mathrm{Pd}(\mathrm{II})$ by $0.25 \mathrm{M}$ green diesel was studied in the $0.5-3 \mathrm{M}$ range by using different nitric acid solutions in the same concentration range and addition of the proper amounts of sodium nitrate which keeps the total nitrate ion concentration in the solution fixed at $3 \mathrm{M}$. When $\log \mathrm{D}$ was plotted against $\log \left[\mathrm{H}^{+}\right]$, a straight line was obtained with slope 0.1 (Figure 2), indicating that no $\mathrm{H}^{+}$was released in the aqueous medium during extraction. This also indicates that the increase in $\left[\mathrm{H}^{+}\right]$in the investigated range had nearly no effect on the extraction of $\mathrm{Pd}(\mathrm{II})$ under the used experimental conditions.

\subsubsection{Effect of nitrate ion concentration}

The effect of nitrate ion concentration on the extraction of $9.40 \times 10^{-4} \mathrm{M} \mathrm{Pd}(\mathrm{II})$ from $\mathrm{HNO}_{3}$ by $0.25 \mathrm{M}$ green diesel in kerosene was studied in the concentration range $3-5 \mathrm{M}$ at constant $\left[\mathrm{H}^{+}\right]$of $3 \mathrm{M}$. The obtained data indicate that when the total nitrate ion concentration increased, the distribution ratio slightly increased. The plot of $\log \mathrm{D}$ versus $\log \left[\mathrm{NO}_{3}\right]$ was found to give a straight line with positive slope of about 0.31 , which indicates that the increase in nitrate ion concentration had a negligible effect on the extraction of $9.40 \times 10^{-4} \mathrm{M}$ of $\mathrm{Pd}(\mathrm{II})$ under the used experimental conditions (Figure 2). 


\subsubsection{Effect of Pd ion concentration}

The effect of Pd(II) concentration on its extraction from $3 \mathrm{M}$ nitric acid by $0.25 \mathrm{M}$ green diesel in kerosene was carried out in the range $\left(4.7 \times 10^{-4}-4.6 \times 10^{-3} \mathrm{M}\right)$. The results indicate that the extraction process decreased with the increase in $\mathrm{Pd}(\mathrm{II})$ concentration. The relation between the equilibrium concentration of $\mathrm{Pd}^{+2}$ in the organic and aqueous phases plotted in Figure 4 indicates that the molar ratio of $\mathrm{Pd}(\mathrm{II})$ to the extractant is equal to $1: 2$ in the extracted metal species, which supports the results represented in Figure 2.

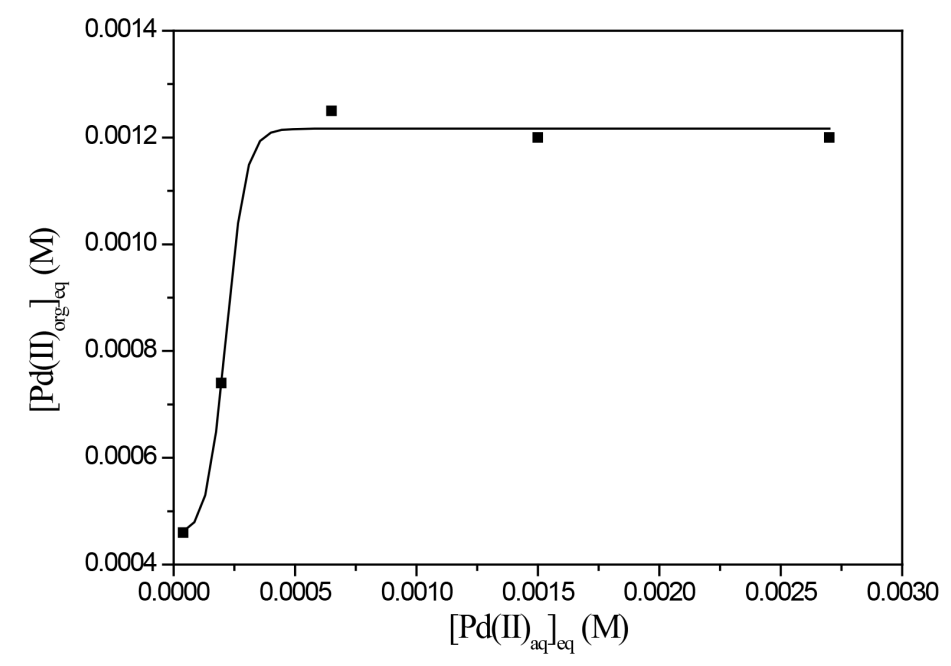

Figure 4: The isotherm of $\mathrm{Pd}(\mathrm{II})$ extraction from $3 \mathrm{M}$ nitric acid solution with green diesel in kerosene; $\mathrm{O}: \mathrm{A}=1: 1, \mathrm{~T}=25^{\circ} \mathrm{C} \pm 1{ }^{\circ} \mathrm{C}$, [diesel] $=0.25 \mathrm{M}$, shaking time $=60 \mathrm{~min}$.

\subsubsection{Extraction equilibrium}

Based on the experimental results and the slope analysis values of the above log$\log$ relations which indicate that 1 mole of Pd(II) chelates with 2 moles of the extractant, and assuming that $\operatorname{Pd}\left(\mathrm{NO}_{3}\right)_{2}$ is the predominant species in the aqueous nitrate medium, the extraction equilibrium of $\mathrm{Pd}$ (II) from nitric acid solution with green diesel can be represented by: ${ }^{16-19}$

$$
\mathrm{Pd}\left(\mathrm{NO}_{3}\right)_{2}+\overline{2 \mathrm{GD}} \rightleftharpoons \overline{\mathrm{Pd}\left(\mathrm{NO}_{3}\right)_{2} .2 \mathrm{GD}}
$$

where GD denotes green diesel extractant. 
The extraction constant $K_{e x}$ can be expressed as (in $\mathrm{M}^{-2}$ ):

$$
\mathrm{K}_{\mathrm{ex}}=\frac{\left[\overline{\mathrm{Pd}\left(\mathrm{NO}_{3}\right)_{2} \cdot 2 \mathrm{GD}}\right]}{\left[\mathrm{Pd}\left(\mathrm{NO}_{3}\right)_{2}\right] \cdot[\overline{\mathrm{GD}}]^{2}}
$$

Since the distribution ratio is given by the relation:

$$
\mathrm{D}=\frac{\left[\mathrm{Pd}\left(\mathrm{NO}_{3}\right)_{2} \cdot 2 \mathrm{GD}\right]}{\left[\mathrm{Pd}\left(\mathrm{NO}_{3}\right)_{2}\right]}
$$

Therefore, the extraction constant is expressed as $\left(\right.$ in $\left.\mathrm{M}^{-2}\right)$ :

$$
\mathrm{K}_{\mathrm{ex}}=\frac{\mathrm{D}}{[\overline{\mathrm{GD}}]^{2}}
$$

The average $\mathrm{K}_{\mathrm{ex}}$ value calculated using Equation 7 at different green diesel concentrations was found to be $58 \pm 0.6 \mathrm{M}^{-2}$.

\subsubsection{Infrared spectroscopic investigations}

To learn about the Pd(II) complex extracted by green diesel in kerosene from nitrate medium, the IR of the organic phase was studied before and after the Pd extraction in the wave length region $4000-450 \mathrm{~cm}^{-1}$.

The IR spectrum of $0.25 \mathrm{M}$ green diesel in kerosene with n-octanol as a modifier before extraction of $\mathrm{Pd}(\mathrm{II})$ showed bands at $2955.1 \mathrm{~cm}^{-1}, 2916.6 \mathrm{~cm}^{-1}$ and $2854.7 \mathrm{~cm}^{-1}$ that belong to aliphatic $\mathrm{C}-\mathrm{H}$ stretching vibrations of $\mathrm{CH}_{3}$ and $\mathrm{CH}_{2}$ present in the extractant which is a mixture of hydrocarbons ${ }^{20}{ }^{20}$ Furthermore, the bands at $1459.1 \mathrm{~cm}^{-1}$ and $1376.8 \mathrm{~cm}^{-1}$ are related to the deformation caused by $\mathrm{CH}_{2}$ groups next to the sulphur atom in green diesel and to the attached $\mathrm{CH}_{3}$ groups. The band at $1096.4 \mathrm{~cm}^{-1}$ is related to the $\mathrm{C}-\mathrm{SH}$ stretching of sulfated diesel. The bands at $721.7 \mathrm{~cm}^{-1}$ and $671.7 \mathrm{~cm}^{-1}$ are due to the stretching vibrations related to C-S bond, shown in Figure 5(a). ${ }^{20}$

After Pd(II) extraction, a new band assigned to the nitrate group appeared at $1652.2 \mathrm{~cm}^{-1}$, shown in Figure 5(b), which indicates the presence of $\mathrm{NO}_{3}^{-}$groups in the extracted metal species and supports the proposed equilibrium reaction given in Equation $4 .^{20}$ 
(a)

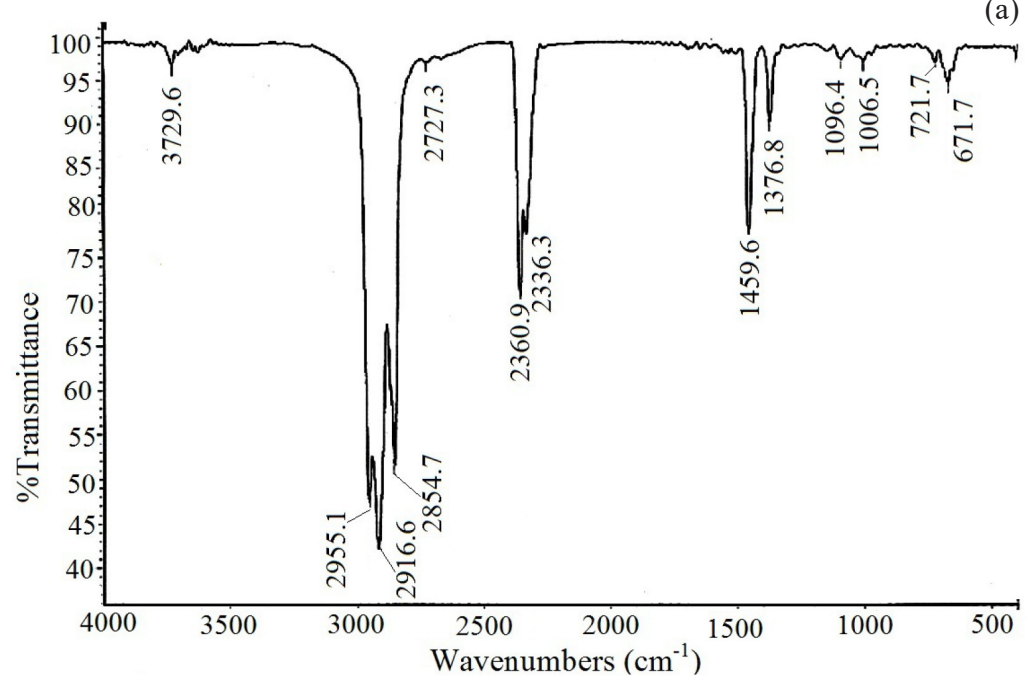

(b)

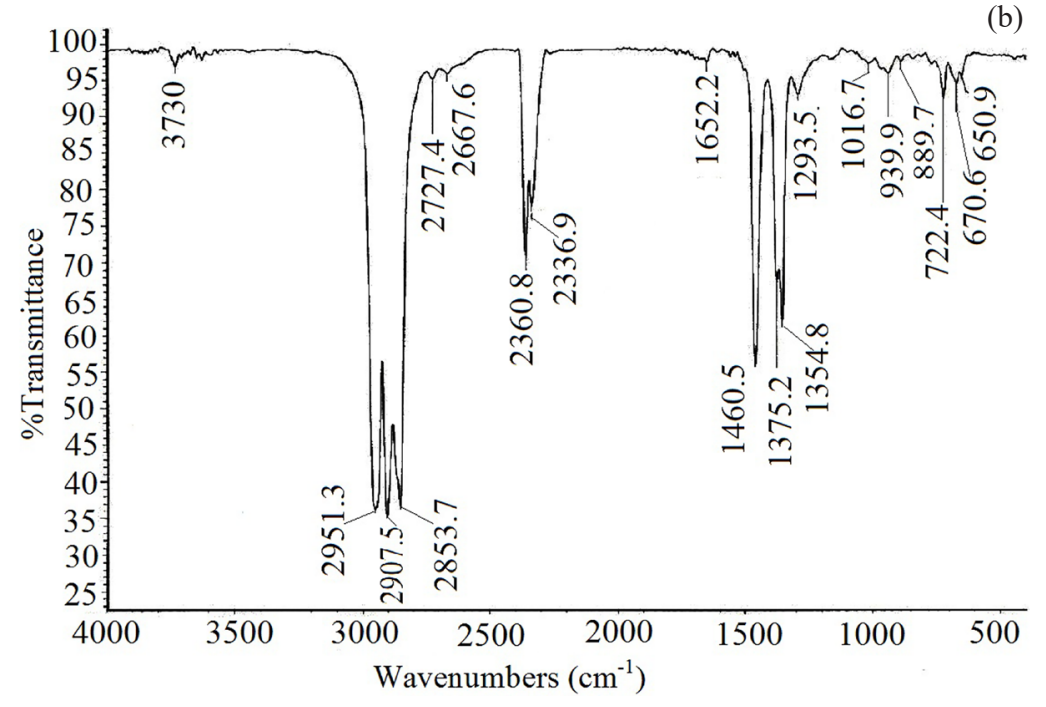

Figure 5: IR spectra of green diesel in kerosene, illustrated for (a) before extraction of $\mathrm{Pd}(\mathrm{II})$, and (b) after extraction of Pd(II).

\subsubsection{Effect of temperature}

The effect of temperature on the extraction of $9.40 \times 10^{-4} \mathrm{M} \mathrm{Pd}(\mathrm{II})$ from $3 \mathrm{M} \mathrm{HNO}_{3}$ using $0.25 \mathrm{M}$ green diesel in kerosene was studied in the $15^{\circ} \mathrm{C}-60^{\circ} \mathrm{C}$ range. The extraction was found to decrease with the increase in temperature. The relation between $(1 / \mathrm{T})$ and the corresponding $\mathrm{K}_{\mathrm{ex}}$ values gave a straight line as shown in 
Figure 6. From the slope of this line and using the van't Hoff equations, the enthalpy change $(\Delta \mathrm{H})$, the entropy change $(\Delta \mathrm{S})$ and free energy change were calculated and the data are given in Table 1 . The negative value of the enthalpy change $(\Delta \mathrm{H})$ indicates that the extraction of $\operatorname{Pd}(\mathrm{II})$ in the investigated system is an exothermic process, with an increase in the randomness of the system shown by the positive value of the entropy change $(\Delta S)$.

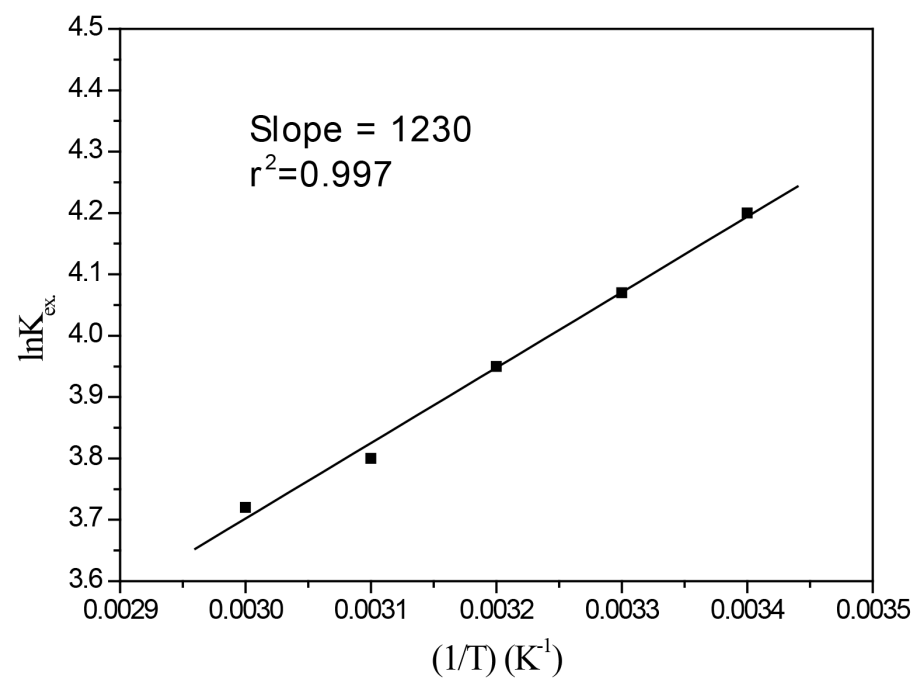

Figure 6: Relation between $\left(\mathrm{K}_{\mathrm{ex}}\right)$ and $(1 / \mathrm{T})$ for the extraction of $\mathrm{Pd}(\mathrm{II})$ with green diesel in kerosene from $3 \mathrm{M}$ nitric acid solution; $\mathrm{O}: \mathrm{A}=1: 1$, shaking time $=60 \mathrm{~min}$, $[$ diesel $]=0.25 \mathrm{M},[\mathrm{Pd}(\mathrm{II})]=9.4 \times 10^{-4} \mathrm{M}$.

Table 1: Thermodynamic parameters of the extraction of $\mathrm{Pd}(\mathrm{II})$ from $3 \mathrm{M} \mathrm{HNO}_{3}$ solution by green diesel in kerosene at phase ratio $\mathrm{O}: \mathrm{A}=1$.

\begin{tabular}{lccc}
\hline Thermodynamic parameter & $\begin{array}{c}\Delta \mathrm{H} \\
\left(\mathrm{kJ} \mathrm{mole}^{-1}\right)\end{array}$ & $\begin{array}{c}\Delta \mathrm{G} \\
\left(\mathrm{kJ} \mathrm{mole}^{-1}\right)\end{array}$ & $\begin{array}{c}\Delta \mathrm{S} \\
\left(\mathrm{J} \mathrm{mole}^{-1} \mathrm{~K}^{-1}\right)\end{array}$ \\
\hline Calculated value & $-10.26 \pm 0.47$ & $-10.00 \pm 0.39$ & $0.87 \pm 0.004$ \\
\hline
\end{tabular}

\subsubsection{Effect of phase ratio}

The effect of organic to aqueous $(\mathrm{O} / \mathrm{A})$ phase ratio on the extraction of $9.40 \times 10^{-4} \mathrm{M} \mathrm{Pd}$ (II) from $3 \mathrm{M} \mathrm{HNO}_{3}$ with $0.25 \mathrm{M}$ green diesel in kerosene was investigated in the range between $1: 2$ and 5:2. The extraction was found to increase with increasing $\mathrm{O} / \mathrm{A}$ phase ratio in the range $1: 2-2: 1$, and the extraction of $\mathrm{Pd}(\mathrm{II})$ was almost complete after reaching the organic to aqueous phase ratio 2 , as shown in Figure 7. 


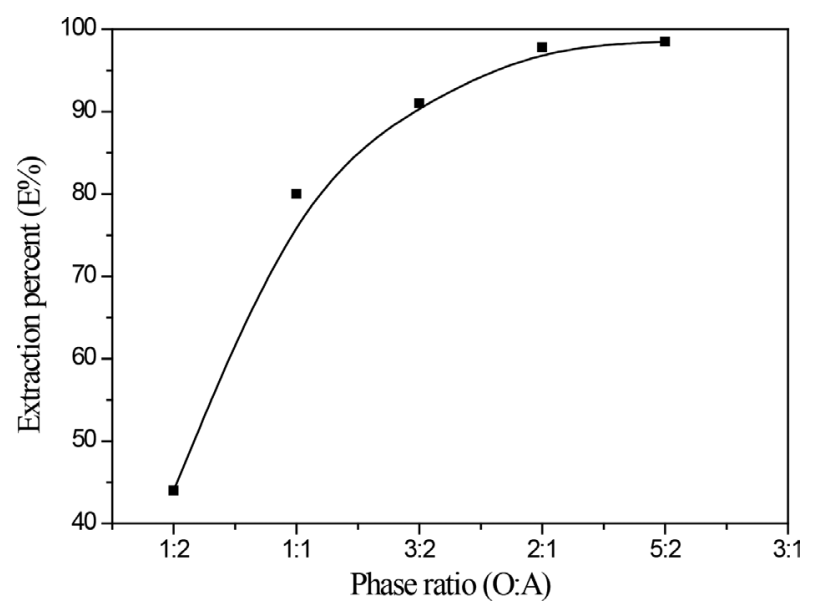

Figure 7: Effect of phase ratio on the extraction of $\mathrm{Pd}(\mathrm{II})$ with green diesel in kerosene from $3 \mathrm{M}$ nitric acid solution; shaking time $=60 \mathrm{~min}, \mathrm{~T}=25^{\circ} \mathrm{C} \pm 1{ }^{\circ} \mathrm{C}$, $[$ diesel $]=0.25 \mathrm{M},[\mathrm{Pd}(\mathrm{II})]=9.4 \times 10^{-4} \mathrm{M}$.

\subsubsection{The loading capacity}

The loading capacity of one mole of green diesel which achieved the extraction of $\mathrm{Pd}(\mathrm{II})$ from $3 \mathrm{M}$ nitric acid solution was determined by shaking an organic solution containing $0.25 \mathrm{M}$ green diesel in kerosene with an equal volume of an aqueous solution containing $9.4 \times 10^{-4} \mathrm{M} \mathrm{Pd}(\mathrm{II})$; after equilibration and separation of the two phases, the amount of the metal loaded in the organic phase was determined. The aqueous phase was discarded and a fresh aqueous solution was used for another round of extraction with the same organic solution. These stages were repeated until the extractant became unable to extract more amounts of $\mathrm{Pd}(\mathrm{II})$. As shown in Figure 8, the maximum concentration of $\mathrm{Pd}(\mathrm{II})$ in the organic phase is $0.001 \mathrm{M}$ and was reached after four extraction stages. This indicates that the maximum loading of green diesel is $2 \times 10^{-2}$ moles of $\mathrm{Pd}(\mathrm{II})$ per mole extractant.

\subsubsection{McCabe-Thiele diagram}

The number of the theoretical stages required for complete Pd extraction by green diesel in kerosene from $3 \mathrm{M}$ nitric acid solution could be determined using the McCabe-Thiele diagram presented in Figure 9. The extraction isotherm which represents the relation between $\mathrm{Pd}(\mathrm{II})$ concentration in the aqueous phase and its concentration in the organic phase was first drawn. The operating line, the slope of which is equal to the phase ratio (O:A) to be used, was then inserted. A vertical line was drawn from the concentration of $\mathrm{Pd}(\mathrm{II})$ in the feed solution on the $\mathrm{X}$-axis, and starting from the point where this vertical line meets the operating line, a 
horizontal line was drawn to the extraction isotherm and then a vertical line to the operating line. This diagram indicates that two extraction stages are sufficient for the extraction of $9.40 \times 10^{-4} \mathrm{M} \mathrm{Pd}$ (II) from $3 \mathrm{M}$ nitric acid with $0.25 \mathrm{M}$ green diesel.

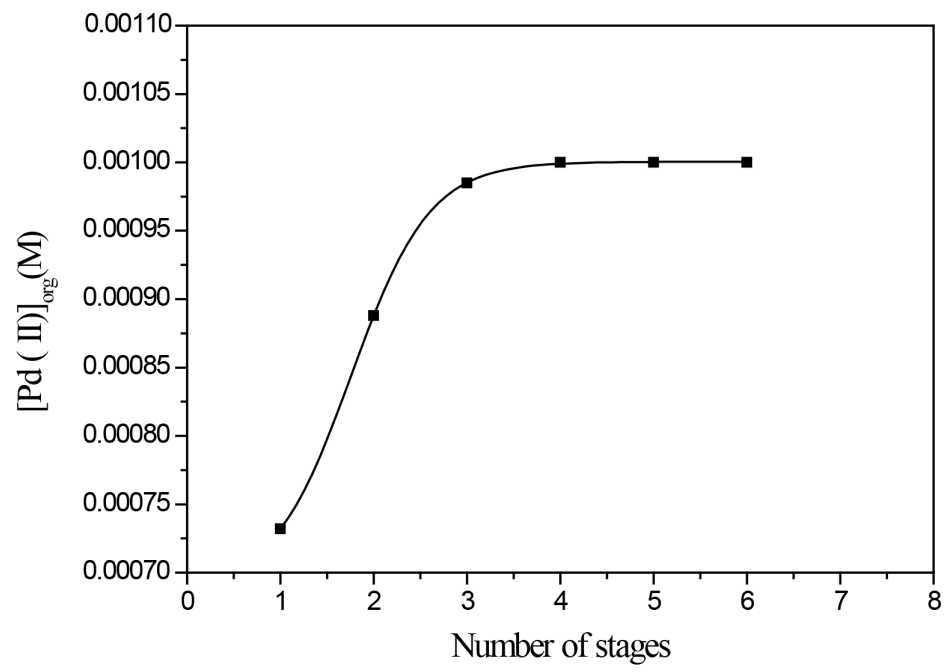

Figure 8: Effect of number of stages on the extraction of $\mathrm{Pd}(\mathrm{II})$ with green diesel in kerosene from $3 \mathrm{M}$ nitric acid solution; $\mathrm{O}: \mathrm{A}=1: 1, \mathrm{~T}=25^{\circ} \mathrm{C} \pm 1{ }^{\circ} \mathrm{C}$, $[$ diesel $]=0.25 \mathrm{M},[\mathrm{Pd}(\mathrm{II})]=9.4 \times 10^{-4} \mathrm{M}$, shaking time $=60 \mathrm{~min}$.

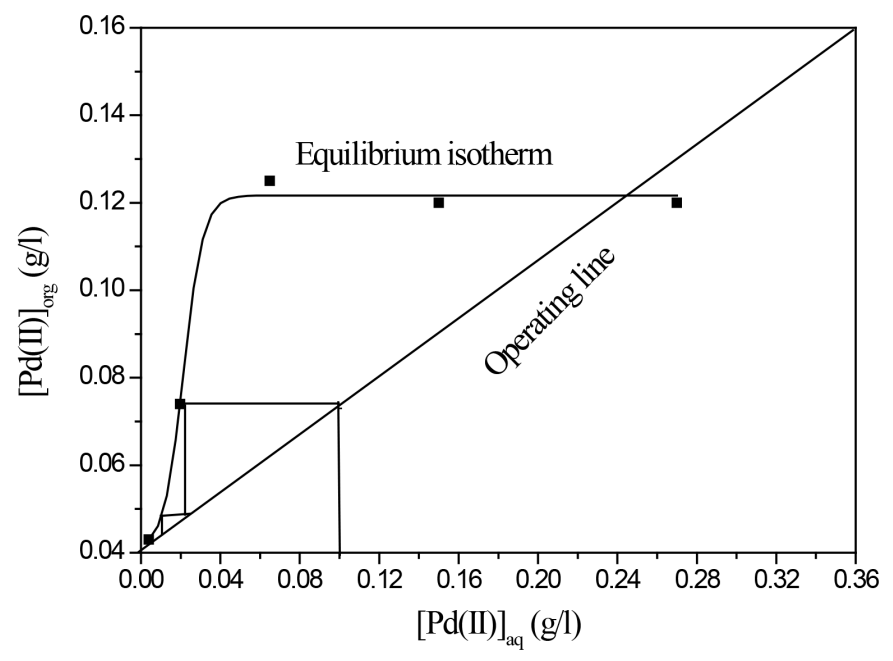

Figure 9: McCabe-Thiele diagram for extraction of $\mathrm{Pd}(\mathrm{II})$ from $\mathrm{HNO}_{3}$ solution by green diesel in kerosene at $25^{\circ} \mathrm{C}$ and $\mathrm{O}: \mathrm{A}=1$. 


\subsubsection{Effect of diluents}

The effect of different diluents such as kerosene, cyclohexane, benzene, toluene, chloroform and carbon tetrachloride on the extraction of $9.40 \times 10^{-4} \mathrm{M}$ Pd from $3 \mathrm{M}$ nitic acid solution by $0.25 \mathrm{M}$ green diesel was carried out. The results shown in Figure 10 indicate that kerosene gave the highest extraction percent and is the most favourable diluent under the used experimental conditions. The values of the dielectric constant $(\varepsilon)$ and the dipole moment $(\mu)$, as well as the extraction percentage of the investigated diluents are given in Table 2 . The decrease in the extraction percentage from $80 \%$ in case of kerosene $(\varepsilon=1.8)$ to $68 \%$ in case of cyclohexane and $\sim 52 \%$ in case of chloroform $(\varepsilon=4.81)$ may be related to the water solubility in the organic phase, which is a factor that decreases the extraction, and is generally low in aliphatic diluents and high in polar molecules and in diluents with high dielectric constant. ${ }^{21}$ On the other hand, the decrease in the extraction process when using benzene or toluene is related to the interaction between the aromatic hydrocarbons and the extractant, which is usually stronger than that of non aromatic ones, and subsequently decreases the metal extraction. ${ }^{22,23}$ This explains the increase in the extraction percentage of $\mathrm{Pd}(\mathrm{II})$ with green diesel in case of kerosene which has a low dipole momemt $(\mu=0)$ compared with toluene or chloroform which have higher values of dipole moment. It has to be mentioned that in addition to its high extraction percent, kerosene is commercially available at low cost and gives a good phase separation, which made it a preference choice for the investigations carried out in this work.

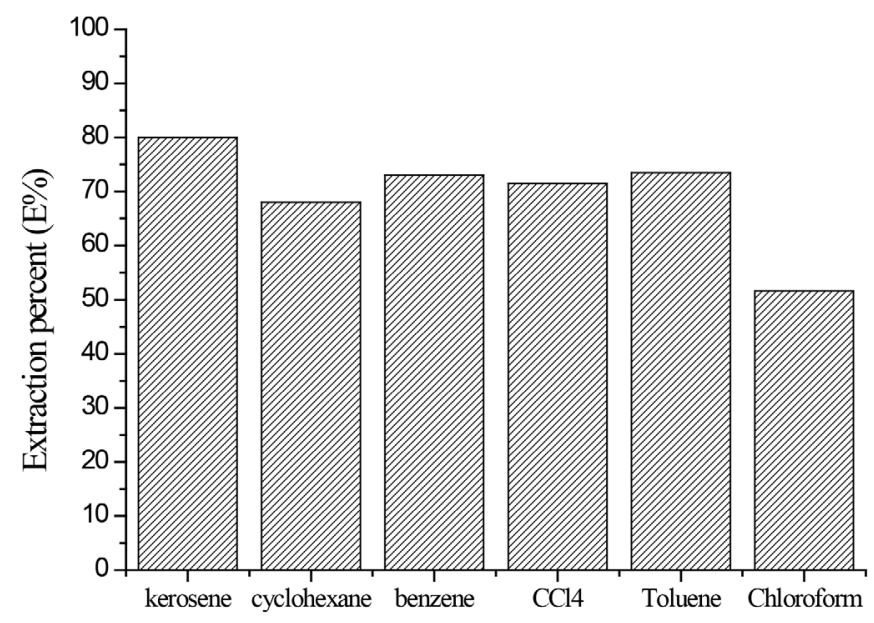

Diluent

Figure 10: Effect of different diluents on the extraction of $\mathrm{Pd}(\mathrm{II})$ from $3 \mathrm{M}$ nitric acid solution using green diesel; $\mathrm{O}: \mathrm{A}=1: 1, \mathrm{~T}=25^{\circ} \mathrm{C} \pm 1^{\circ} \mathrm{C},[\mathrm{Pd}(\mathrm{II})]=9.4 \times 10^{-4} \mathrm{M}$, $[$ diesel $]=0.25 \mathrm{M}$, shaking time $=60 \mathrm{~min}$. 
Table 2: The effect of different diluents on the extraction of $9.4 \times 10^{-4} \mathrm{M} \mathrm{Pd}(\mathrm{II})$ from $3 \mathrm{M}$ nitric acid solution by $0.25 \mathrm{M}$ green diesel.

\begin{tabular}{lccc}
\hline Diluent & Extraction percent & Dipole moment $(\mu)$ & Dielectric const. $(\varepsilon)$ \\
\hline Kerosene & 80 & 0 & 1.8 \\
Cyclohexane & 68 & 0 & 2.02 \\
Carbon tetrachloride & 71.5 & 0 & 2.24 \\
Benzene & 73 & 0 & 2.27 \\
Toluene & 73.5 & 0.43 & 2.38 \\
Chloroform & 51.6 & 1.15 & 4.81 \\
\hline
\end{tabular}

\subsubsection{Extraction of Pd(II) from other acidic media}

Most of the leaching processes for PGMs in hydrometallurgy, especially Pd, are generally carried out with hydrochloric and sulfuric acids. Therefore, the extraction of $9.40 \times 10^{-4} \mathrm{M}$ Pd by $0.25 \mathrm{M}$ green diesel in kerosene from these media was studied in the acid concentration range of $0.5-5 \mathrm{M}$. The results shown in Figure 11 indicate that the extraction of Pd(II) from chloride medium increased with the increase in the acid concentration and reached its maximum at $1 \mathrm{M} \mathrm{HCl}$ due to the salting out effect of the chloride ions which increased with the increase in $\mathrm{HCl}$ concentration up to $2 \mathrm{M}$. This effect becomes negligible due to the known tendency of Pd to form stable chlorocomplexes at high acidities, which is an obvious reason for the decrease in the distribution ratio of $\mathrm{Pd}^{7,13,24,25} \mathrm{In}$ addition, the decrease in the metal extraction with the increase in the acidity of the medium may be also related to the possible extraction of $\mathrm{HCl}$ leading to the decrease in the concentration of the extractant available for Pd(II) extraction .

The extraction of $\mathrm{Pd}(\mathrm{II})$ from sulfuric acid medium was found to be more efficient, where the extraction percentage increased from $72 \%$ to $95 \%$ with increasing the acid concentration from $0.5 \mathrm{M}$ to $5 \mathrm{M}$ (Figure 10). The extraction of Pd from nitric acid, hydrochloric and sulfuric acid media was found to decrease in the order $\mathrm{H}_{2} \mathrm{SO}_{4}>\mathrm{HNO}_{3}>\mathrm{HCl}$.

\subsection{Stripping Process}

The loaded organic phase containing $7.5 \times 10^{-4} \mathrm{M} \mathrm{Pd}(\mathrm{II})$ after extraction from $3 \mathrm{M}$ nitric acid with $0.25 \mathrm{M}$ green diesel in kerosene was stripped with various concentrations of different stripping agents namely, citric acid, oxalic acid, $\mathrm{HNO}_{3}, \mathrm{H}_{2} \mathrm{SO}_{4}, \mathrm{HCl}, \mathrm{NaOH}$, aqueous ammonia, $\mathrm{NaCl}$, thiourea, $\mathrm{NH}_{4} \mathrm{SO}_{4}$, EDTA, ammonium thiocyante and $\mathrm{Na}_{2} \mathrm{CO}_{3}$, as well as $\mathrm{H}_{2} \mathrm{O}$ at equal phase ratio and shaking time $60 \mathrm{~min}$. The values of the stripping percent were calculated and are given in 
Table 3. The tabulated data show that a maximum of $98.5 \%$ stripping was achieved with $0.5 \mathrm{M}$ ammonium thiocyante solution; $97 \%$ of $\mathrm{Pd}(\mathrm{II})$ was stripped with $0.5 \mathrm{M}$ ammonium acetate or ammonium hydroxide. However, an efficient stripping of $96 \%$ was obtained with $0.05 \mathrm{M}$ thiourea or ammonium thiocyante; other stripping agents gave low stripping percent. The effect of time on the stripping with 0.05 ammonium thiocyante indicated that 45 min was sufficient for stripping more than $98 \%$ of the loaded $\mathrm{Pd}(\mathrm{II})$ in one stage and further increase in the shaking time decreased the stripping percent, as shown in Figure 12.

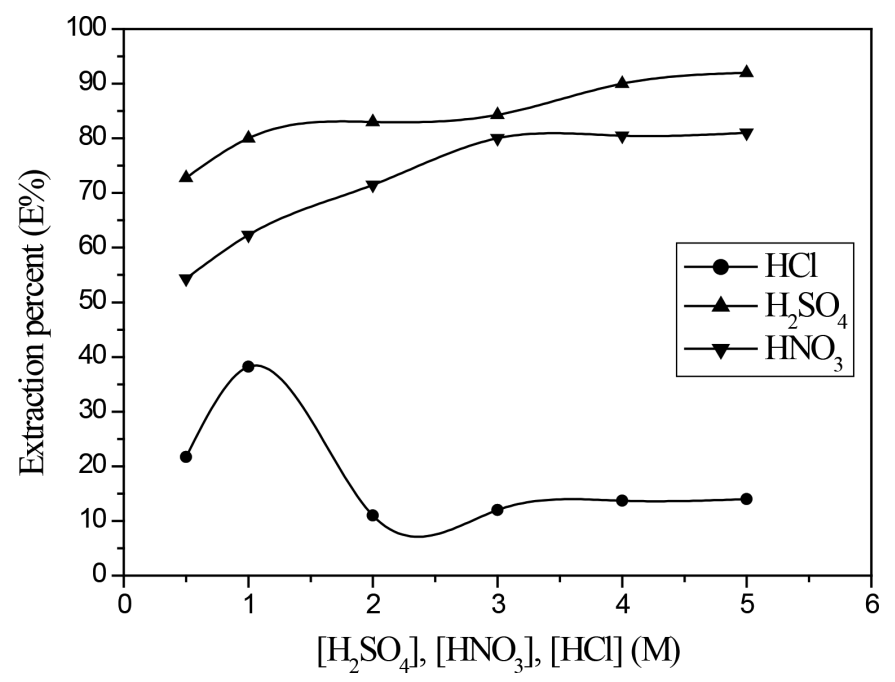

Figure 11: Effect of acid concentration on the extraction of $\operatorname{Pd}(\mathrm{II})$ by green diesel in kerosene from $\mathrm{H}_{2} \mathrm{SO}_{4}, \mathrm{HNO}_{3}$ and $\mathrm{HCl}$ solutions; $\mathrm{O}: \mathrm{A}=1: 1, \mathrm{~T}=25^{\circ} \mathrm{C} \pm 1{ }^{\circ} \mathrm{C}$, $[$ diesel $]=0.25 \mathrm{M},[\mathrm{Pd}(\mathrm{II})]=9.4 \times 10^{-4} \mathrm{M}$, shaking time $=60 \mathrm{~min}$.

Table 3: Stripping percent of $9.4 \times 10^{-4} \mathrm{M} \mathrm{Pd}(\mathrm{II})$ from loaded $0.25 \mathrm{M}$ green diesel in kerosene.

\begin{tabular}{lll}
\hline Stripping agent & Conc. (M) & Stripping \% \\
\hline $\mathrm{H}_{2} \mathrm{O}$ & - & 5 \\
& & \\
[Thiourea $]$ & 0.01 & 95.50 \\
& 0.05 & 96.0 \\
& 0.1 & 98 \\
& 0.5 & 98 \\
\hline
\end{tabular}

(continued on next page) 
Table 3:(Continued)

\begin{tabular}{|c|c|c|}
\hline Stripping agent & Conc. (M) & Stripping \% \\
\hline$\left[\mathrm{NH}_{4} \mathrm{SCN}\right]$ & $\begin{array}{l}0.01 \\
0.05 \\
0.1 \\
0.25 \\
0.50\end{array}$ & $\begin{array}{l}95 \\
96 \\
98 \\
98 \\
98.50\end{array}$ \\
\hline [Ammonium acetate] & $\begin{array}{l}0.1 \\
0.5 \\
1.0\end{array}$ & $\begin{array}{l}77.50 \\
97.0 \\
94\end{array}$ \\
\hline [Ammonium nitrate] & 0.50 & 20 \\
\hline [Ammonium sulphate] & 0.5 & 30 \\
\hline Aqueous ammonia & $\begin{array}{l}0.15 \\
0.5 \\
1.0\end{array}$ & $\begin{array}{l}52.50 \\
97 \\
98\end{array}$ \\
\hline$[\mathrm{NaOH}]$ & $\begin{array}{l}0.5 \\
1\end{array}$ & $\begin{array}{l}38.0 \\
40\end{array}$ \\
\hline$[\mathrm{NaCl}]$ & $\begin{array}{l}0.75 \\
1 \\
2.0\end{array}$ & $\begin{array}{l}35 \\
37 \\
40\end{array}$ \\
\hline$\left[\mathrm{Na}_{2} \mathrm{CO}_{3}\right]$ & $\begin{array}{l}0.5 \\
1\end{array}$ & $\begin{array}{l}38 \\
40\end{array}$ \\
\hline $\mathrm{H}_{2} \mathrm{SO}_{4}$ & $\begin{array}{l}0.50 \\
1\end{array}$ & $\begin{array}{l}9 \\
11.50\end{array}$ \\
\hline $\mathrm{HCl}$ & $\begin{array}{l}0.50 \\
1\end{array}$ & $\begin{array}{l}30 \\
36.50\end{array}$ \\
\hline $\mathrm{HNO}_{3}$ & $\begin{array}{l}1 \\
5\end{array}$ & $\begin{array}{l}8 \\
6\end{array}$ \\
\hline Citric acid & $\begin{array}{l}0.50 \\
1\end{array}$ & $\begin{array}{l}15 \\
21.50\end{array}$ \\
\hline Oxalic acid & $\begin{array}{l}0.25 \\
1\end{array}$ & $\begin{array}{l}47.30 \\
47.80\end{array}$ \\
\hline EDTA & $\begin{array}{l}0.1 \\
2.0\end{array}$ & $\begin{array}{l}62.50 \\
40\end{array}$ \\
\hline
\end{tabular}




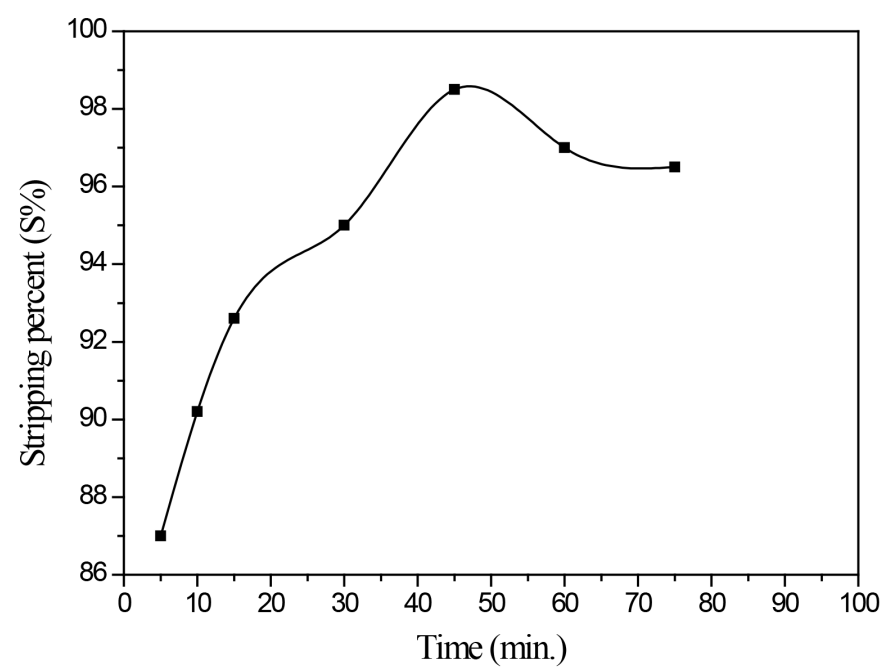

Figure 12: Effect of time on the stripping of $\mathrm{Pd}(\mathrm{II})$ loaded on green diesel in kerosene with $0.05 \mathrm{M}$ ammonium thiocyanate; $\mathrm{O}: \mathrm{A}=1: 1, \mathrm{~T}=25^{\circ} \mathrm{C} \pm 1{ }^{\circ} \mathrm{C},\left[\mathrm{NH}_{4} \mathrm{SCN}\right]=$ $0.05 \mathrm{M}$.

\subsection{Industrial Application on Spent Automotive Catalyst}

Catalytic converters, which allow the purification of automotive exhaust emissions, contain significant amounts of platinum group metals (PGM), especially Pd, Pt and $\mathrm{Rh}$. Spent automobile catalytic converters which are considered as the main secondary source of PGM, are recycled by the metallurgical industry, through the use of pyro and/or hydrometallurgical methods. When the matrix containing PGM is leached in acidic media, $\mathrm{Pd}, \mathrm{Pt}$ and $\mathrm{Rh}$ would be separated using conventional techniques such as solvent extraction and ion exchange. In this context, and in order to test the viability of the investigated extraction system for the recovery of $\mathrm{Pd}$ (II) from the spent automotive catalysts, a developed process is proposed and discussed.

\subsubsection{Leaching process}

A spent automotive catalyst supplied from Magar Brothers service center (Egypt) was grounded to a mesh size less than 300 mesh. Chemical analysis of the catalyst powder was carried out by X-ray fluorescence (XRF) analysis and the results are given in Table 4. The tabulated data indicate that the spent catalysts contains $0.114 \mathrm{wt} \% \mathrm{Pd}, 0.032 \mathrm{wt} \% \mathrm{Rh}, 4.8 \mathrm{wt} \%$ zirconium and high percent of cerium and other rare earth elements. 
Table 4: XRF analysis of the used sample of automotive spent catalyst.

\begin{tabular}{lc}
\hline Metal & Weight (\%) \\
\hline $\mathrm{Pd}(\mathrm{II})$ & 0.114 \\
$\mathrm{Rh}(\mathrm{III})$ & 0.032 \\
$\mathrm{Zr}(\mathrm{IV})$ & 4.80 \\
$\mathrm{Zinc}(\mathrm{II})$ & 0.062 \\
$\mathrm{Ni}(\mathrm{II})$ & 0.342 \\
$\mathrm{Fe}(\mathrm{III})$ & 16.230 \\
$\mathrm{Al}(\mathrm{III})$ & 19.749 \\
$\mathrm{Si}(\mathrm{IV})$ & 9.315 \\
$\mathrm{~Pb}(\mathrm{II})$ & 0.327 \\
\hline
\end{tabular}

Different characterisation techniques were also used for the evaluation of the physicochemical properties of the spent catalyst and the residue. In this context, scanning electron microscopic (SEM) analysis was used to study the morphology of the spent automotive catalyst and the SEM analysis of the powdered catalyst was performed at magnification of 200X and 1000X, shown in Figure 13. Energy dispersive X-ray analysis (EDX) was also carried out to investigate the quantitative analysis of metals present in the spent automotive catalyst; the EDX spectrum of the spent catalyst shown in Figure 14 indicates that the major elements are cerium, alumina, silicon, Pd and others.
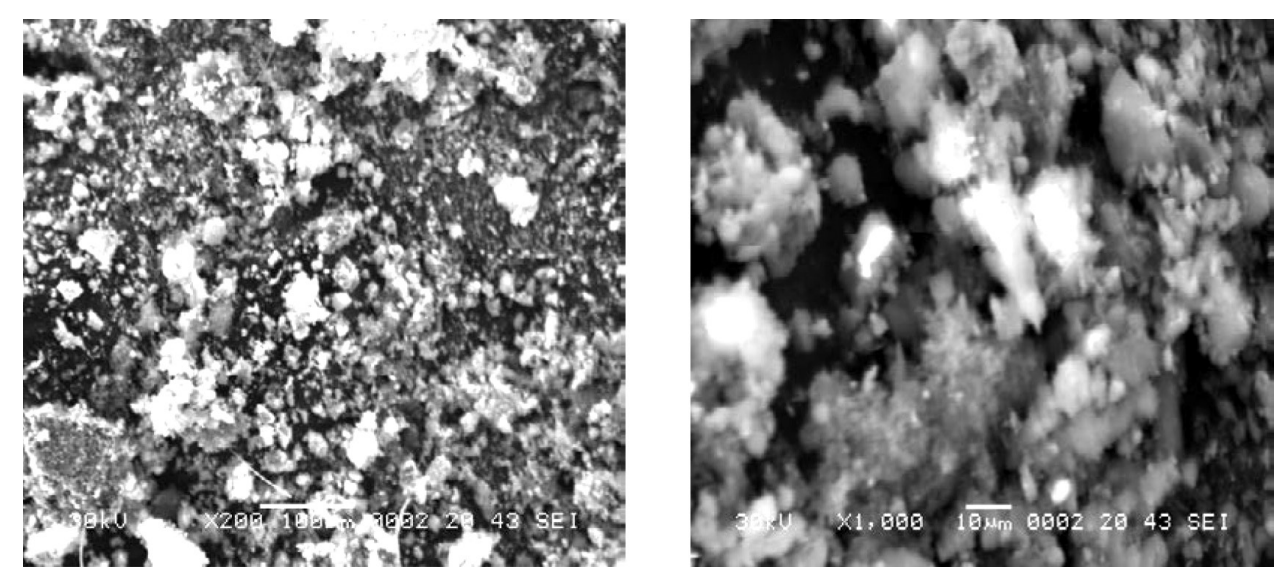

Figure 13: SEM images of the used spent automotive catalyst (magnification 200X on the left, and $1000 \mathrm{X}$ on the right). 


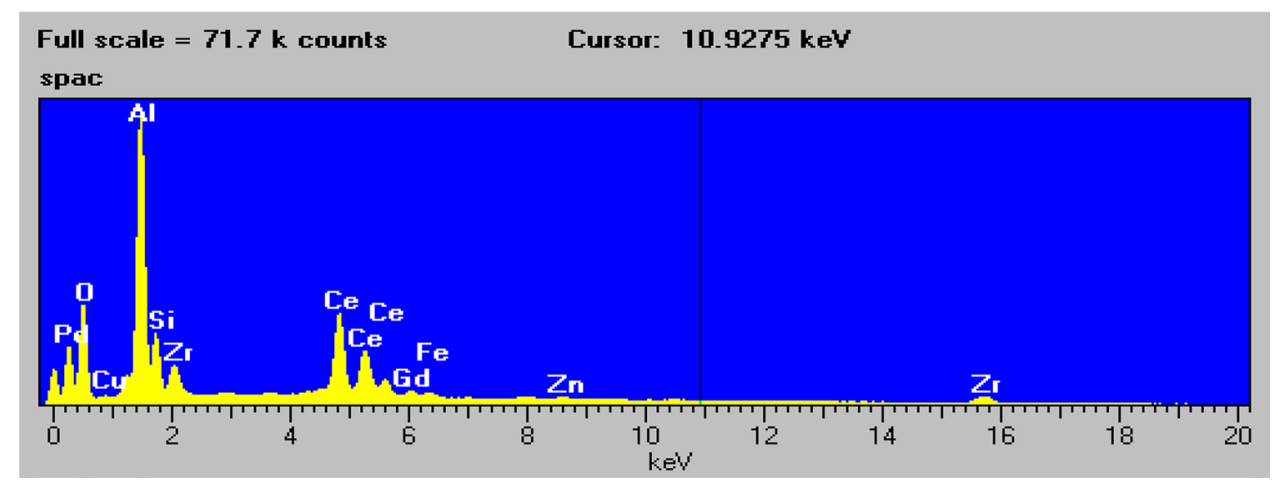

Figure 14: EDX analysis of the used spent automotive catalyst.

A sample weighing $15 \mathrm{~g}$ of the grounded catalyst powder was digested with two leaching solutions, namely aqua regia and $\left(10 \mathrm{H}_{2} \mathrm{SO}_{4}: 1 \mathrm{H}_{2} \mathrm{O}_{2}\right)$ solution at $60^{\circ} \mathrm{C}-70^{\circ} \mathrm{C}$ for $2 \mathrm{~h}$. The results indicated that $\mathrm{H}_{2} \mathrm{SO}_{4}-\mathrm{H}_{2} \mathrm{O}_{2}$ mixture was a better leaching solution. The leached sample solution was scanned using a prodigy high dispersion Inductively Coupled Plasma Optical Emission Spectroscope (ICPOES), Leeman, USA, after dilution to $100 \mathrm{ml}$ with deionised water and the results are given in Table 6.

Table 6: ICP-OES analysis of leached solution of the used spent catalyst before and after extraction using $0.25 \mathrm{M}$ green diesel in kerosene.

\begin{tabular}{lcc}
\hline Metal & Conc. (before extraction), ppm & Conc. (after extraction), ppm \\
\hline $\mathrm{Pd}(\mathrm{II})$ & 160 & 16 \\
$\mathrm{Rh}(\mathrm{III})$ & 100 & 98 \\
$\mathrm{Zr}(\mathrm{IV})$ & 69.6 & 67.0 \\
$\mathrm{Zn}(\mathrm{II})$ & 1.5 & 1.30 \\
$\mathrm{Mn}(\mathrm{III})$ & 0.4 & 0.4 \\
$\mathrm{Fe}(\mathrm{III})$ & 20.50 & 20.0 \\
$\mathrm{Al}(\mathrm{III})$ & 879.20 & 874.0 \\
$\mathrm{Cu}(\mathrm{II})$ & 2 & 1.9 \\
$\mathrm{~Pb}(\mathrm{II})$ & 10.4 & 9 \\
$\mathrm{Cs}(\mathrm{II})$ & 0.6 & 0.5 \\
$\mathrm{Cr}(\mathrm{III})$ & 0.4 & 0.4 \\
$\mathrm{Si}(\mathrm{IV})$ & 15.0 & 15.0 \\
\hline
\end{tabular}




\subsubsection{Extraction process}

Based on the experimental data and the results given in section 3.1.14 for extraction of $\mathrm{Pd}(\mathrm{II})$ from sulphuric acid medium, $25 \mathrm{ml}$ of the leached solution (diluted to 4 $\left.\mathrm{M} \mathrm{H}_{2} \mathrm{SO}_{4}\right)$ was shaken with $25 \mathrm{ml}$ solution of $0.25 \mathrm{M} \mathrm{(6 \% )} \mathrm{green} \mathrm{diesel} \mathrm{in} \mathrm{kerosene}$ at phase ratio $\mathrm{O}: \mathrm{A}=1: 1 \mathrm{in}$ two stages for $60 \mathrm{~min}$. After extraction and separation of the two phases, the aqueous phase was analysed by ICP-OES and the results given in Table 4 indicate that Pd extraction percent was about $90 \%$ while the extraction percent of the other metals collected was less than $1 \%$. On the other hand, Pd loaded in the organic phase was stripped with $0.05 \mathrm{M}$ ammonium thiocyante at equal O:A phase ratio, and the regenerated extractant was used for another cycle. The proposed process for the recovery of Pd from a spent automotive catalyst in sulphuric acid in summarised in Figure 15.

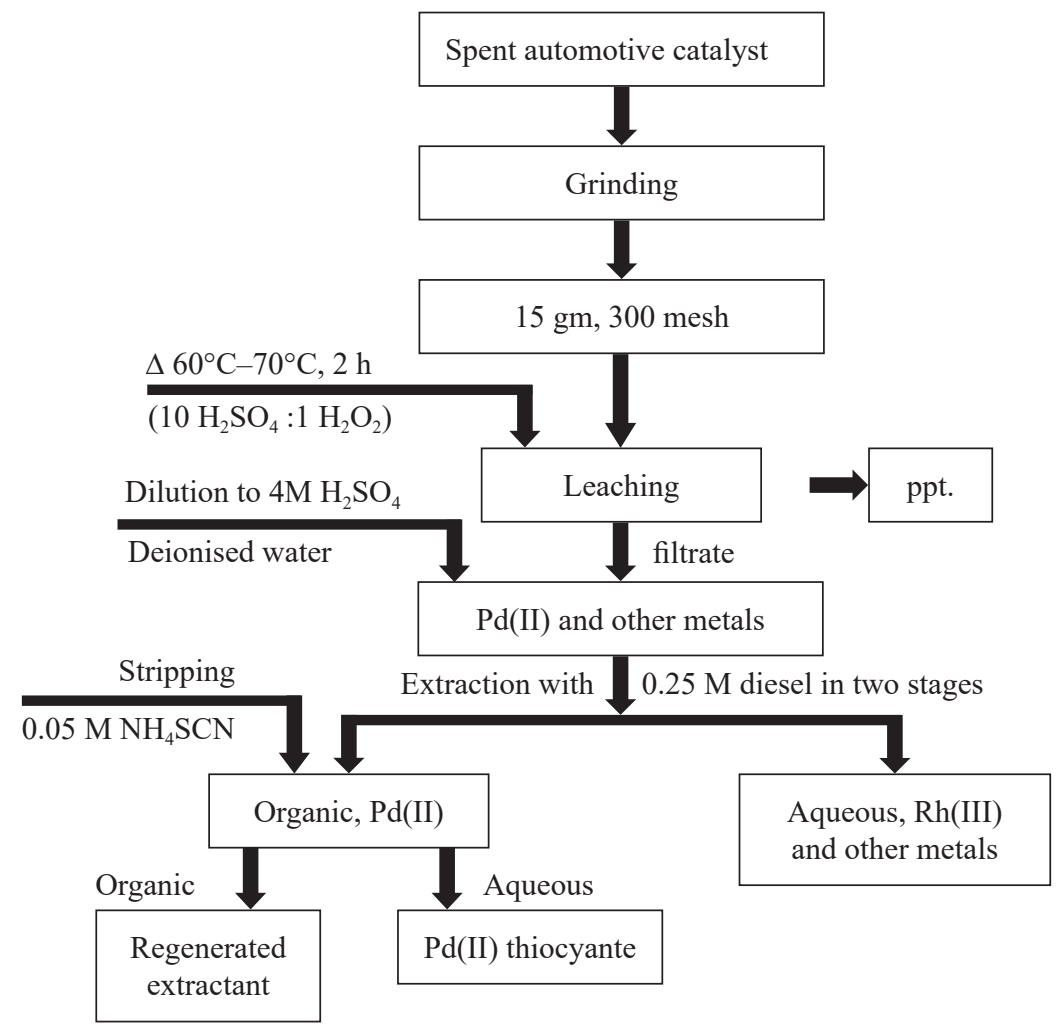

Figure 15: Flowchart for the recovery of Pd(II) from automotive spent catalyst in sulphuric acid solution. 


\section{CONCLUSION}

Green diesel has high extraction ability towards Pd ions from nitrate medium and the extraction equilibrium was reached after $60 \mathrm{~min}$. The stoichiometry of the extracted metal species was determined as [Pd $\left(\mathrm{NO}_{3}\right)_{2}$.2GD.], where GD denotes green diesel. The mean value of the extraction constant equals $58 \pm 0.6 \mathrm{M}^{-2}$, under the used experimental conditions. Increasing temperature had an inhibiting effect on the extraction of $\mathrm{Pd}$ indicating the exothermic nature of the extraction process. The loading capacity of one mole of green diesel was found to be $2 \times 10^{-2}$ moles of $\mathrm{Pd}(\mathrm{II})$ per mole extractant. Pd was strongly stripped from the organic phase using different stripping agents; $0.05 \mathrm{M}$ of thiourea or ammonium thiocyante had a stripping efficiency of about $96 \%$ and $98 \%$, respectively. The effect of diluents on the extraction of Pd(II) from nitric acid solution by green diesel indicated that, under the used experimental conditions, kerosene gave the highest extraction percent compared to cyclohexane, benzene, toluene, chloroform and carbon tetrachloride. Green diesel could also extract $\mathrm{Pd}$ (II) from hydrochloric and sulfuric acid media with higher extraction from sulfuric acid solution. The extraction from the investigated acidic media took the sequence $\mathrm{H}_{2} \mathrm{SO}_{4}>\mathrm{HNO}_{3}>\mathrm{HCl}$. Based on the results obtained, a developed process for the recovery of $\mathrm{Pd}(\mathrm{II})$ from the sulphate leach solution of spent automotive catalyst using green diesel was proposed and the obtained results indicate the efficiency of the proposed process.

\section{ACKNOWLEDGEMENTS}

The work presented in this paper was supported by the Hot Laboratories Centre, Egyptian Atomic Energy Authority (EAEA).

\section{REFERENCES}

1. Othman, N. et al. (2014). Liquid-liquid extraction of palladium from simulated liquid waste using phosphinic acid as a carrier. J. Teknol., 68(5), 41-45, https://doi.org/10.11113/jt.v68.3029.

2. Cole, P. M., Sole, K. C. \& Feather, A. M. (2006). Solvent extraction developments in Southern Africa. Tsinghua Sci. Technol., 11, 153-159, https://doi.org/10.1016/S1007-0214(06)70169-9.

3. Hung, N. T., Watanabe, M. \& Kimura, T. (2007). Solvent extraction of palladium(II) with various ketones from nitric acid medium. Solv. Extr. Ion Exch., 25(3), 407-416, https://doi.org/10.1080/07366290701285538.

4. Noweir, H. G. (2014). Separation and purification of palladium from aqueous solution by thiol derivatives. Arab J. Nucl. Sci. Appl., 47(1), 53-60. 
5. Turanov, A. N., Karandashev, V. K. \& Proshin, A. N. (2008). Extraction of palladium(II) from nitric acid solutions with 1-benzoyl-3-[6-(3-benzoylthioureido)-hexyl] thiourea. Solv. Extr. Ion Exch., 26, 360-474, https://doi. org/10.1080/07366290802182865.

6. Gupta, B. \& Singh, I. (2013). Extraction and separation of platinum, palladium and rhodium using CYANEX 923 and their recovery from real samples. Hydrometal., 134-135, 11-18.

7. El-Hefny, N. E. \& Daoud, J. A. (2013). Solvent extraction of palladium(II) from aqueous chloride medium by triphenylphosphine, triphenylphosphine oxide or triphenylphosphine sulphide in benzene. J. Phys. Sci., 24(2), 3547.

8. Ahmed, I. M., Nayl, A. A. \& Daoud, J. A. (2011). Extraction of palladium from nitrate solution by CYANEX 471. Int. J. Miner. Process., 101, 89-93, https://doi.org/10.1016/j.minpro.2011.07.009.

9. Pan, L., Bao, X. \& Gu, G. (2013). Solvent extraction of palladium (II) and effective separation of palladium (II) and platinum (IV) with synthetic sulfoxide MSO. Min. Metall. Sect. B-Metall., 49(1), 57-63.

10. Regel-Rosocka, M. et al. (2015). Removal of palladium(II) from aqueous chloride solutions with cyphos phosphonium ionic liquids as metal ion carriers for liquid-liquid extraction and transport a polymer inclusion membranes. Physicochem. Probl. Miner. Process., 51(2), 621-631.

11. Cieszynska, A. \& Wisniewski, M. (2010). Extraction of palladium(II) from chloride solutions with Cyphos IL 101/toluene mixtures as novel extractant. Sep. Sci. Technol., 73, 202-210, https://doi.org/10.1016/j. seppur.2010.04.001.

12. American Chemical Society. (1989). Chemical abstracts 110. Washington: American Chemical Society.

13. Př́íhoda, J. (1979). Extraction of $\mathrm{Pd}(\mathrm{II})$ by some petrochemical products from nitrate media. J. Radioanal. Chem., 51, 233-243, https://doi. org/10.1007/BF02520493.

14. U.S. Department of Health and Human Services. (1995). Public health service toxicological profile for fuel oils. Atlanta: U.S. Department of Health and Human Services.

15. Anil, W. (2011). Analytic combustion with thermodynamics chemical kinetics and mass transfer. Cambridge: Cambridge University Press.

16. Zaitsev, B. N. \& In'kova, E. N. (1981). Palladium distribution in the palladium nitrate-sodium nitrate- nitric acid- tributtl phosphate-decane system. Radiokhimiya, 23(6), 817-820.

17. El-Reefy, S. A., Daoud, J. A. \& Aly, H. F. (1992). Extraction of palladium from nitrate solution by triphenylphosphine or triphenylaphosphine oxide in chloroform. J. Radioanal. Nucl. Chem. Art., 158(2), 303-312, https://doi.org/10.1007/BF02047117. 
18. Kassem, A. T. et al. (2017). Extraction of palladium from nitrate medium by emulsion liquid membrane containing CYANEX 471X as carrier. Solv. Extr. Ion Exch., 35(2), 145-160, https://doi.org/10.1080/07366299.2017.1 279910.

19. Colthup, N. B., Daly, L. H. \& Wiberley, S. E. (1990). Introduction to infrared and raman spectroscopy, 3rd ed. New York: Academic Press.

20. Healy, T. V. (1961). Synergism in the extraction of di-, tri- and tetravalent metal ions - II. Synergic effects in so-called inert diluents J. Inorg. Nucl. Chem., 19, 328-339, https://doi.org/10.1016/0022-1902(61)80122-X.

21. Sekine, T. \& Hasegawa, Y. (1977). Solvent extraction chemistry: Fundamentals and applications. New York: Marcel Dekker.

22. Saji, J. (2002). Studies on liquid-liquid extraction separation of valuable metals from titania wastes. PhD diss., the Ion-specific Separation Science and Technology Group of Regional Research Laboratory (CSIR), Thiruvananthapuram, India.

23. Burger, K. (1964). Coordination chemical and analytical problems of the application of organic metal reagents. Acta Chem. Acad. Sci. Hung., 40, 261.

24. Barakat, M. A., Mahmoud, M. H. H. \& Mahrous, Y. S. (2006). Recovery and separation of palladium from spent catalyst. Appl. Catal. A Gen., 142, 387, https://doi.org/10.1016/j.apcata.2005.11.028.

25. Crundwell, F. K. et al. (2011). Extractive metallurgy of nickel, cobalt and platinum-group metals. Amsterdam: Elsevier. 